\title{
Mapeamento de dimensões socioeconômicas para o desenvolvimento da educação a distância: uma visão a partir de municípios mineiros
}

\author{
Mapping of socioeconomic dimensions for the development of distance \\ education: a vision from mining municipalities \\ Mapeo de dimensiones socioeconómicas para el desarrollo de la educación a \\ distancia: una visión desde los municípios mineros
}

ROBERTA DE CÁSSIA MACEDO

http://orcid.org/0000-0002-5191-3542

Centro Universitário UNA

Faculdade de Administração de Empresas Departamento de Logística e Gestão Financeira

Contagem, MG, Brasil

\section{DANIELA VIEGAS DA COSTA NASCIMENTO \\ http://orcid.org/0000-0002-0260-2342 \\ Centro Universitário UMA \\ Faculdade de Administração de Empresas \\ Núcleo de Ética e Gestão Social \\ Contagem, MG, Brasil \\ IARA VAZ VIEIRA DE SOUSA \\ https://orcid.org/0000-0002-5974-2354 \\ Centro Universitário UMA \\ Faculdade de Arquitetura e Urbanismo \\ Contagem, MG, Brasil}

\begin{abstract}
Resumo: O trabalho apresenta uma pesquisa exploratório-descritiva conduzida sob base documental em municípios de Minas Gerais divididos nos 17 territórios de desenvolvimento, com recorte amostral de 30 a 100 mil habitantes, nos anos de 2016 a 2018. O objetivo é analisar as dimensões socioeconômicas para o desenvolvimento da educação à distância. As variáveis e os dados foram colhidos a partir do Índice Mineiro de Responsabilidade Social (IMRS). Os resultados demonstram que há territórios em situação de maior vulnerabilidade, enquanto outros apresentam resultados propensos a educação a distância.
\end{abstract}

Palavras-chave: Socioeconômico; EaD; IMRS. 


\begin{abstract}
This paperpresents an exploratory-descriptive research, conducted on a documentary basis in municipalities of Minas Gerais divided into 17 development territories, with a sample size of 30 to 100 thousand inhabitants, in the years from 2016 to 2018. The objective is to analyze the socioeconomic dimensions for the development of distance education. The variables and data were collected from the Minas Gerais Social Responsibility Index (IMRS). The results demonstrate that there are territories in a situation of greater vulnerability, while others present results prone to distance education.
\end{abstract}

Keywords: Socioeconomic; EaD; IMRS.

Resumen: El trabajo presenta una investigación exploratoria descriptiva realizada en forma documental en municipios de Minas Gerais divididos en 17 territorios, con un tamaño de 30 a 100 mil habitantes, en los años 2016 a 2018. El objetivo es analizar las dimensiones socioeconómicas para el desarrollo de la educación a distancia. Las variables y los datos fueron recolectados del Índice de Responsabilidad Social de Minas Gerais (IMRS). Los resultados demuestran que hay territorios en una situación de mayor vulnerabilidad, mientras que otros presentan resultados propensos a la educación a distancia.

Palabras-clave: Socioeconómico; EaD; IMRS.

\title{
INTRODUÇÃO
}

Cidades de várias regiões do mundo estão implementando ações para serem mais inteligentes, criando soluções fortemente baseadas no emprego de tecnologia. Quer-se melhorar a vida das pessoas, ampliar a qualidade da gestão dos recursos e contar com a participação cidadã (PRZEYBILOVICZ; CUNHA; MEIRELLES, 2018).

Diante das características singulares da sociedade brasileira, sobretudo quanto aos aspectos social, econômico, educacional e de infraestrutura, verifica-se um panorama heterogêneo de desenvolvimento e desigualdades (SOUZA, 2015). Nesse cenário, ao aprofundar no aspecto educacional, chega-se à modalidade do ensino a distância. Essa modalidade de ensino pode favorecer o acesso a cursos formativos e profissionalizantes para a população que possui dificuldade de frequentar o ensino tradicional.

Fahel e Teles (2018) relatam a necessidade de fomentar a ascensão da população de baixo nível socioeconômico, aspirando à diminuição da pobreza, por meio do fortalecimento das políticas sociais voltadas à educação. Essas ações, em médio e longo prazos, possibilitam a implantação de novas práticas que busquem a promoção da educação e consequentemente da trabalhabilidade. Para tal, é imprescindível o entendimento das condições existentes nos municípios mineiros para construção de propostas. 
Este trabalho propõe a realização de uma análise socioeconômica dos municípios mineiros para verificar se eles apresentam condições favoráveis para a expansão da educação superior à distância. Com embasamento teórico voltado para questões sociais e educacionais, visa-se à análise de fatores que fortaleçam as políticas públicas relacionadas à educação superior à distância. Destaca-se que o presente trabalho integra o Projeto FAPEMIG Demanda Universal 01/2017 n. APQ-02118-17, aprovado, intitulado "Dimensões para o desenvolvimento da educação superior a distância: análise das perspectivas relativas à infraestrutura tecnológica e à realidade socioeconômica dos municípios mineiros".

Para a análise, fez-se necessário distinguir e operar variáveis indicativas do desenvolvimento educacional e da gestão socioeconômica dos municípios mineiros a partir do Índice Mineiro de Responsabilidade Social (IMRS). Entretanto, para implantar a educação a distância é preciso compreender a realidade socioeconômica dos municípios mineiros, em prol da educação a distância. Esse estudo pretende trazer luz ao tema ao identificar elementos socioeconômicos que possibilitem reflexões sobre a educação a distância, na realidade mineira.

Nesse sentido, o artigo organiza-se em Referencial Teórico em sua primeira parte, seguido dos Procedimentos Metodológicos, que detalham os passos da pesquisa de campo. Na Análise dos Resultados, cada variável foi estudada separadamente por meio de gráficos que possibilitam análises comparativas entre os territórios de Minas Gerais. Por fim, apresenta-se a Conclusão, ressaltando os principais aspectos do trabalho.

\section{QUESTÕES SOCIOECONÔMICAS E DESENVOLVIMENTO LOCAL}

São poucas as ferramentas e metodologias capazes de avaliar a questão da desigualdade no Brasil. As diferenças territoriais, por exemplo, são um problema permanente (ARAUJO e FLORES, 2017; MESQUITA et al., 2015). O Produto Interno Bruto (PIB) per capita, muitas vezes utilizado como parâmetro de análise, é insuficiente para contextos e economias díspares, visto que esta dimensão não abarca as situações de bem-estar social (ARAUJO e FLORES, 2017; KAKWANI \& SON, 2008).

Apesar de, nos últimos anos, o debate e a proposição de políticas públicas ter se expandido (MOURA, 2010), consolidando articulações para minimizar os efeitos da desigualdade, o cenário apresenta percalços, pois muitas análises são baseadas no economicismo (SOUZA, 2009; 2013) e não revelam um diagnóstico mais completo dos problemas e desafios do contexto público brasileiro, o que pode reforçar o processo de desigualdade social no país. 
Fahel e Teles (2018) relatam a necessidade de fomentar a ascensão da população de baixo nível socioeconômico, aspirando à diminuição da pobreza, por meio do fortalecimento das políticas sociais voltadas à educação. Esses desafios precisam "influenciar a concepção e implementação de políticas sociais, para que se tornem mais eficazes e inovadoras em termos de focalização nos problemas e contribuam para mudanças mais rápidas no bem-estar da população mais pobre" (FAHEL; TELES, 2018, p.22).

Essa desigualdade dificulta o acesso de todas as regiões aos recursos e infraestrutura para seus cidadãos viverem com qualidade suficiente. Essa diferença entre territórios pode, de acordo com Araujo e Flores (2017), localizar a riqueza em determinados pontos do país, o que afetaria a dinâmica interna do mercado de trabalho ao direcionar profissionais para poucos locais de desenvolvimento especializado. Desse processo, resultaria uma instabilidade política e socioeconômica (LEVY e CHOWDHURY, 1995).

Esse cenário evidencia um quadro para a operação de políticas públicas a partir de cortes sociais, "articuladas a políticas macroeconômicas que garantam um crescimento econômico sustentado; a geração de emprego; a elevação da renda proveniente do trabalho e, sobretudo, a redistribuição de renda ainda altamente concentrada no Brasil." (SILVA, 2010, p. 156).

Para o desenvolvimento local, a vertente econômica deve estar atrelada às dimensões sociais, ambientais, culturais e políticas (MARTINS; VAZ; CALDAS, 2010), sendo o local não uma determinação exclusiva do tamanho, mas do "conjunto de relações que existem em um determinado território seja ele uma microrregião ou uma cidade, considerando as heterogeneidades e especificidades do lugar" (SANTOS e RODRÍGUEZ-GARAVITO, 2006, p. 21). Assim como o território, ao se pensar no desenvolvimento, deve-se centrar nos atores que o compõem e na institucionalidade local, com seus potenciais e perspectivas de transformação social (MARTINS; VAZ; CALDAS, 2010).

Um efetivo desenvolvimento local demanda que seus atores, sejam eles políticos, econômicos, religiosos, culturais, sociais entre outros, trabalhem buscando alinhamento entre os valores locais e as necessidades humanas, para proporcionar soluções que atendam a coletividade. Santos e RodríguezGaravito (2006) destacam o papel da sociedade civil como fundamental para o desenvolvimento dessa dinâmica de crescimento que favoreça a inclusão tanto socioeconômica quanto política.

Os objetivos, portanto, se encaminham para um equilíbrio entre recursos e necessidades, em que a educação exerce influência crucial (FAVARO e TUMOLO, 2016). Pensada como um elemento fundante de um projeto estratégico local, a educação necessita ter a finalidade da superação das desigualdades, para 
o desenvolvimento pleno. Por isso a educação é um componente-força da economia, já que ela oferece bases para a inovação, incentivo ao desenvolvimento tecnológico e social. Um baixo investimento em educação denota uma sociedade com menor capacidade de articulação e potencial de mudanças benéficas. O investimento em educação proporciona um crescimento mais estável, de bases fortes e com continuidade.

A natureza emancipatória da educação, somada ao questionamento reconstrutivo, buscam autonomia crítica e criativa das pessoas (DEMO, 2011). Para a plenitude dessa transformação social, a educação necessita se ressignificar e suscitar sua visão revolucionária de territórios e ideias para a solução das desigualdades, sobretudo em contextos tão desiguais, como é o caso brasileiro.

A partir das características da sociedade brasileira, principalmente quanto aos aspectos social, econômico, educacional e de infraestrutura, observa-se um cenário heterogêneo de desenvolvimento e desigualdades (SOUZA, 2015). Tornase essencial a construção de políticas públicas de desenvolvimento. Ao considerar o aspecto educacional, chega-se à modalidade do ensino a distância em que a implantação dos cursos formativos pode auxiliar na amplitude do desenvolvimento local. Por este caminho, busca-se a emancipação das pessoas, por sua capacidade de escolha e exercício da crítica (TENÓRIO, 2010; CANÇADO, 2013).

A dimensão do desenvolvimento local transcende a mensuração de variáveis econômicas ao levar em conta as potencialidades, aspectos culturais, sociais, naturais (TENÓRIO, 2010). Por isso, o desenvolvimento local pode ser potencializado com o incentivo à educação, na medida em que ela sustenta uma melhor articulação e inserção dos indivíduos para a integração e criação de ações para transformação local (FISCHER et al, 2006), a fim de atingir resultados cada vez mais estruturais.

Os fins sociais e os meios para atingi-los não podem prescindir da participação de diferentes indivíduos, suas visões, interesses e necessidades, em relações dialógicas (BOULLOSA e SCHOMMER, 2008), com objetivos de fomentar um conjunto de estratégias que asseguram e promovam o emprego e autoemprego com base no desenvolvimento endógeno (SACHS, 2012).

Questões derivadas da maneira pela qual as tecnologias da informação e da comunicação (TICs) evoluíram, tais como controle sobre a rede, produção de conhecimento, desigualdade de acesso são evidentes e permanecem no contexto atual (JUNQUEIRA, et al., 2012). Parece relevante, portanto, discutir para qual tipo de democracia se avança de forma a ampliar os espaços de participação por meio da educação e do desenvolvimento local. No tópico a seguir, discute-se a modalidade EaD como possível caminho e possibilidade. 


\section{EDUCAÇÃO A DISTÂNCIA (EAD) COMO CAMINHO FORMATIVO}

A EaD é uma modalidade de ensino que insere a ideia de flexibilidade na forma de estudar, além de estimular a autonomia do aluno no processo de ensinoaprendizagem. Essa modalidade atende a população que possui dificuldades para frequentar cursos presenciais. Algumas dessas dificuldades são: i) deslocamento para outra cidade, ii) falta de tempo para cumprir com a carga horária presencial, iii) padrão financeiro incompatível com as mensalidades, entre outros.

Nesse sentido, Aretio (2002) ressalta que os principais atributos dos estudantes dessa modalidade são heterogêneos na idade e nas competências, são de diferentes cidades, a aprendizagem é independente e trabalham sendo o estudo como atividade secundária.

$\mathrm{Na} \mathrm{EaD,} \mathrm{as} \mathrm{Tecnologias} \mathrm{de} \mathrm{Informação} \mathrm{e} \mathrm{Comunicação} \mathrm{(TICs)}$ impulsionam essa modalidade, já que as TICs facilitam a interação entre os envolvidos no processo educativo e viabilizam a construção dos saberes (VIEIRA e ABREU, 2016). Entretanto, para que a EaD seja uma realidade nos municípios mineiros, também é necessário que eles possuam uma estrutura socioeconômica capaz de suportar essa modalidade. Pereira (2003, p.20) ressalta que "O ensino a distância é adequado aos adultos que, por razões de ordem social, econômica ou educacional, não podem frequentar cursos regulares (...)".

A EaD encurta o caminho entre o aluno e a escola. Para Moore e Kearsley (1996) é uma aprendizagem programada que demanda projeto de curso e técnicas instrucionais específicas, além de comunicação digital. Tolentino et al. (2013) apontam diversas vantagens e desvantagens dessa modalidade de ensino. Algumas vantagens são: i) supressão de dificuldades geográficas ao ensino; ii) expansão da capilaridade de cursos; iii) desenvolvimento do comportamento proativo dos alunos; iv) redução de custos operacionais.

Tais vantagens corroboram com Vieira e Abreu (2016) que afirmam que a EaD proporciona a oportunidade de realização de uma formação superior e aumento na perspectiva de crescimento profissional. Nesse cenário, a Educação a Distância pode ser vista como um importante recurso para atender alunos situados em diversos locais, e que possuem restrições de tempo e recursos financeiros para se adequarem às exigências da educação presencial.

Em contrapartida, as desvantagens apontadas por Tolentino et al. (2013) são: i) limitação da socialização; ii) dificuldade em aprimorar habilidades comportamentais e afetivas; iii) empobrecimento na troca de experiências; iv) necessidade de planejamento operacional rígido; v) aumento da complexidade dos sistemas de apoio ao ensino. 
Tais dificuldades podem ser compreendidas como desafios inerentes à modalidade de ensino a distância. Contudo, essas desvantagens não são maiores que a ampliação do direito à educação às pessoas que, por alguma razão, se encontravam à margem do sistema educacional.

\section{PROCEDIMENTOS METODOLÓGICOS}

A pesquisa classifica-se como de natureza exploratório-descritiva quanto ao tipo de abordagem e envolve procedimentos metodológicos de coleta de dados documental e bibliográfica. Apresenta-se como uma pesquisa quantitativa, a partir da base de dados do Índice Mineiro de Responsabilidade Social (IMRS), que utiliza a divisão dos municípios mineiros em 17 territórios de desenvolvimento.

Existem vários índices brasileiros com dados sobre a situação socioeconômica, educação e renda de sua população. Entretanto, esses índices, muitas vezes, se apresentam ora defasados, ora com dados de épocas variadas, dificultando a comparação e a credibilidade da pesquisa. Por este motivo, o IMRS foi escolhido por apresentar dados recentes e, pela qualidade e variedade de dados específicos por município mineiro, garantindo maior confiabilidade e detalhamento das informações analisadas.

Os Territórios de Desenvolvimento correspondem à atual regionalização empregada pelo Governo Estadual de Minas Gerais, na qual seus 853 municípios foram agrupados em "áreas que possuem interesses socioeconômicos e geográficos em comum” (MINAS GERAIS, 2015). São dezessete Territórios (Figura 1), com suas respectivas quantidades de municípios em parêntesis: Alto Jequitinhonha (24), Caparaó (55), Central (17), Mata (93), Médio e 16 Baixo Jequitinhonha (35), Metropolitano (79), Mucuri (29), Noroeste (30), Norte (86), Oeste (56), Sudoeste (35), Sul (118), Triângulo do Norte (30), Triângulo do Sul (27), Vale do Aço (34), Vale do Rio Doce (55) e Vertentes (50). 


\section{Figura 1 - Territórios de Desenvolvimento de Minas Gerais}

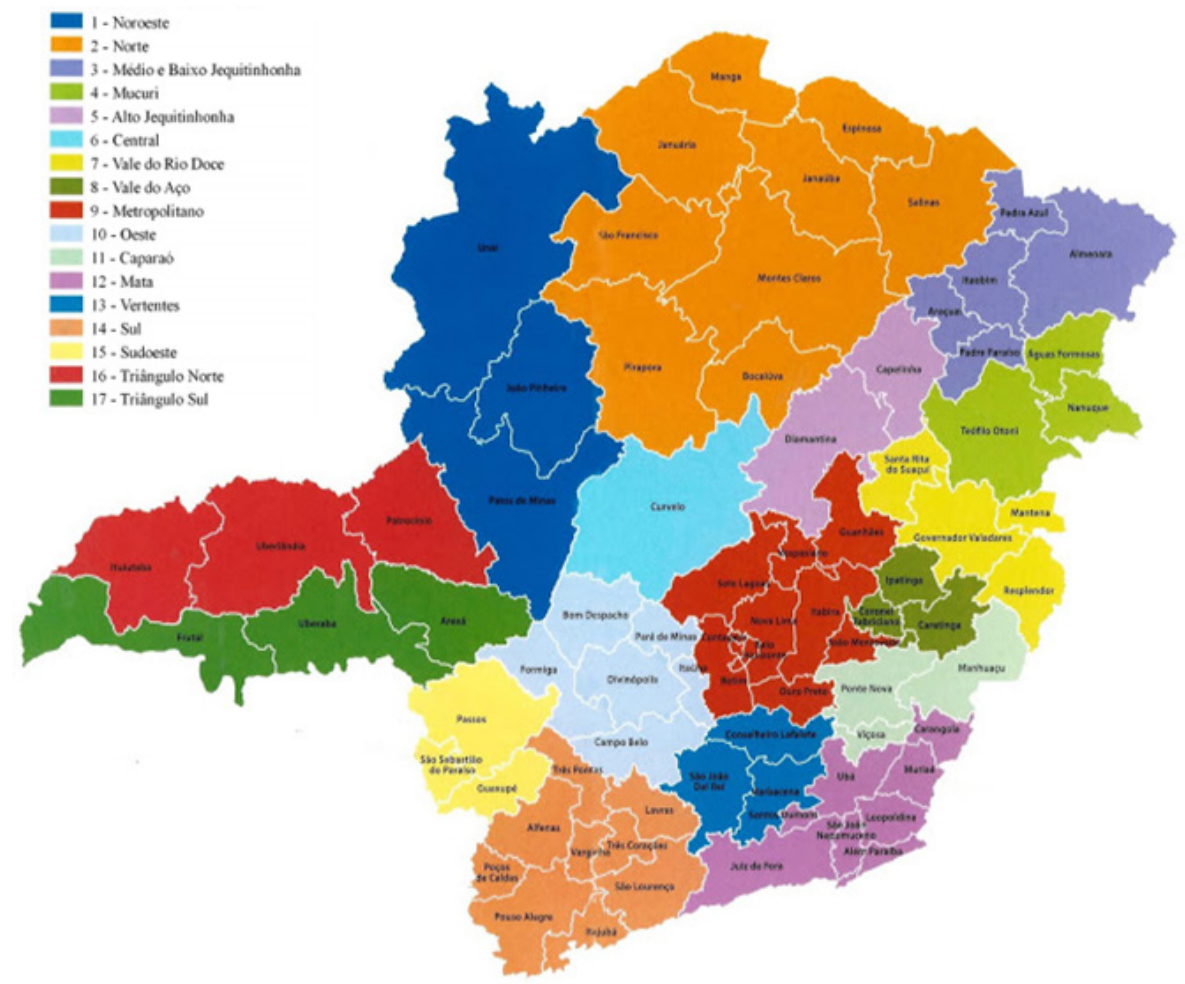

Fonte: Fundação João Pinheiro (2018).

Este estudo utilizou dados dos anos de 2016 a 2018, com recorte amostral de municípios com 30 a 100 mil habitantes. Esse recorte foi determinado em função do objetivo de pesquisa, porque representa uma classificação intermediária entre os municípios de grande porte e os de pequeno porte. Ao buscar entender as condições socioeconômicas dos municípios, de forma a compreender o cenário e analisar suas condições para a futura implementação da educação a distância, avaliou-se que se os municípios muito grandes fossem selecionados, a pesquisa não traria tanto efeito, visto que a presença das redes de ensino já é exaustiva, portanto, eliminaria a necessidade deste estudo. Por outro lado, se os municípios de pequeno porte fossem selecionados para este estudo, outras condições eliminariam a participação desses municípios na amostra, visto que condições de acesso à infraestrutura e internet seriam necessárias para a implantação de programas de educação a distância. 
Em um primeiro momento, o recorte de 30 a 100 mil habitantes por município parece viável para o estudo, pois representam municípios de porte médio, que ainda não têm amplo acesso das redes de ensino nesses locais, mas que podem apresentar condições de desenvolvimento da educação à distância. A triagem possibilita a organização dos dados, facilitando a comparação dos indicadores selecionados nos territórios. Em estudos futuros, pretende-se analisar também os outros municípios, sobretudo os de pequeno porte, para que o acesso à educação seja ampliado e garantido a toda a população.

Os procedimentos metodológicos se deram em cinco fases: 1. Entrevista com a coordenadora do IMRS, para entendimento da lógica de dados classificados no sistema; 2. Mapeamento dos índices que compõem o IMRS; 3. Cruzamento dos índices existentes no IMRS com os objetivos da pesquisa; 4. Seleção dos indicadores do IMRS que contribuiriam diretamente para este estudo; 5. Análise dos indicadores selecionados e comparação dos dados.

Para compreender a situação socioeconômica dos municípios e sua condição para a educação à distância, fez-se necessário o desmembramento dos índices que compõem o IMRS. A fim de responder ao problema de pesquisa, definiu-se que os construtos referentes à Educação (escolaridade, acesso e gestão) e Renda e Emprego (renda das famílias, emprego e gestão) eram mais alinhados, chegando-se aos seis indicadores do Quadro 1. Em seguida, foi feita uma amostragem da população, adotando a seleção de 30 a 100 mil habitantes, na qual obteve-se 16 territórios e 85 municípios. O território do Vale do Aço não se enquadrou na filtragem da população, por isso aparece com informações nulas.

\section{Quadro 1 - Definição dos Indicadores deste Estudo a partir do IMRS}

\begin{tabular}{|l|l|l|l|}
\hline \multicolumn{2}{|c|}{ EDUCAÇÃO } & \multicolumn{2}{c|}{ RENDA E EMPREGO } \\
\hline Escolaridade & $\begin{array}{l}\text { Percentual da população de 25 anos ou mais } \\
\text { com ensino médio completo }\end{array}$ & $\begin{array}{l}\text { Renda das } \\
\text { Famílias }\end{array}$ & Renda per capita \\
\hline Acesso & $\begin{array}{l}\text { Total de escolas que oferecem o Ensino Médio } \\
\text { Regular }\end{array}$ & Emprego & $\begin{array}{l}\text { Rendimento médio dos ocupados-18 anos } \\
\text { ou mais }\end{array}$ \\
\hline Gestão & Gasto per capita com atividades de educação & Gestão & Gasto per capita total \\
\hline
\end{tabular}

Fonte: elaboração das autoras.

Essas variáveis foram escolhidas por serem determinantes para o desenvolvimento social e econômico. Além de possibilitarem possíveis investimentos na área. 


\section{ANÁLISE DOS RESULTADOS}

Cada variável foi analisada separadamente por meio de gráficos que possibilitam análises comparativas entre os territórios de Minas Gerais. Nesse sentido, iniciaram-se as avaliações pelo construto Educação.

O Gráfico 1 mostra os dados da variável Escolaridade. Essa variável apresenta o percentual da população de 25 anos ou mais com ensino médio completo. O objetivo dessa variável é demonstrar se a população dos territórios mineiros possui a formação mínima para cursar um ensino superior.

\section{Gráfico 1 - Percentual da população de 25 anos ou mais com ensino médio completo}

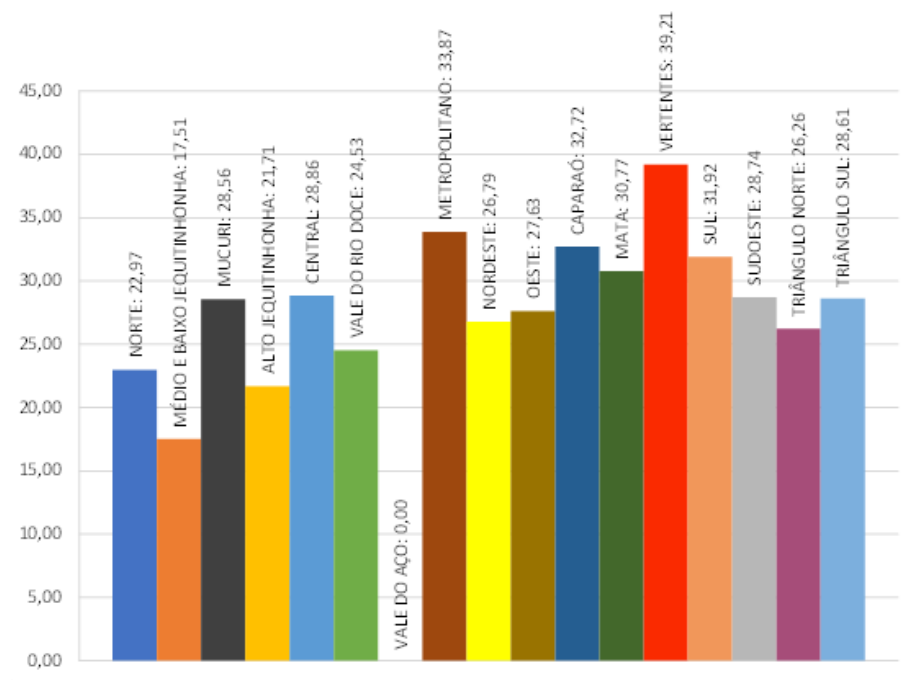

Fonte: IMRS, 2018.

Conforme pode ser visto no Gráfico 1, o território com menor percentual da população acima de 25 anos com ensino médio completo é o "Alto Jequitinhonha” (17,51\%). Já o território com maior número de pessoas acima de 25 anos com ensino médio completo é o território das "Vertentes" (39,23\%), seguido pelo território "Metropolitano" com 33,87\%.

O território das Vertentes também aponta o maior índice do Índice de Desenvolvimento Humano Municipal - IDHM (PNUD; IPEA; FJP, 2013), com o valor de 0,758 , quando comparado aos outros Territórios Mineiros. Nota-se, ao mesmo tempo, que é o segundo maior com número de habitantes, sendo adjacente à região metropolitana. 
Entretanto, nas outras regiões com menores percentuais, respectivamente têm seu IDHM menor, são eles: Norte, Médio e Baixo Jequitinhonha, Alto Jequitinhonha, Vale do Rio Doce. Nota-se também que os territórios que estão com uma média baixa estão próximos a região Nordeste do Brasil. Segundo o IBGE (2012), a contribuição do Nordeste no PIB estadual foi de 4\%. Mais de $74 \%$ dos municípios desse território têm participação inferior a $1 \%$ na atividade econômica regional.

O Gráfico 2 mostra a variável Acesso. Essa variável apresenta o total de escolas que oferecem o Ensino Médio Regular. O objetivo dessa variável é demonstrar se a população mineira possui acesso a esse nível escolar dentro do território em que se vive.

Andrade e Dachs (2007) afirmam que o maior deliberativo do acesso e continuidade a educação, para um vínculo entre idade, curso e série, é a renda familiar. Esse fator impacta em decorrências significantes e acumulativas, resultando em retardo e evasão escolar nas classes mais baixas. Esses dados refletirão na ampla divergência nos percentuais de acessibilidade aos níveis mais altos de ensino.

\section{Gráfico 2 - Total de escolas que oferecem o Ensino Médio Regular}

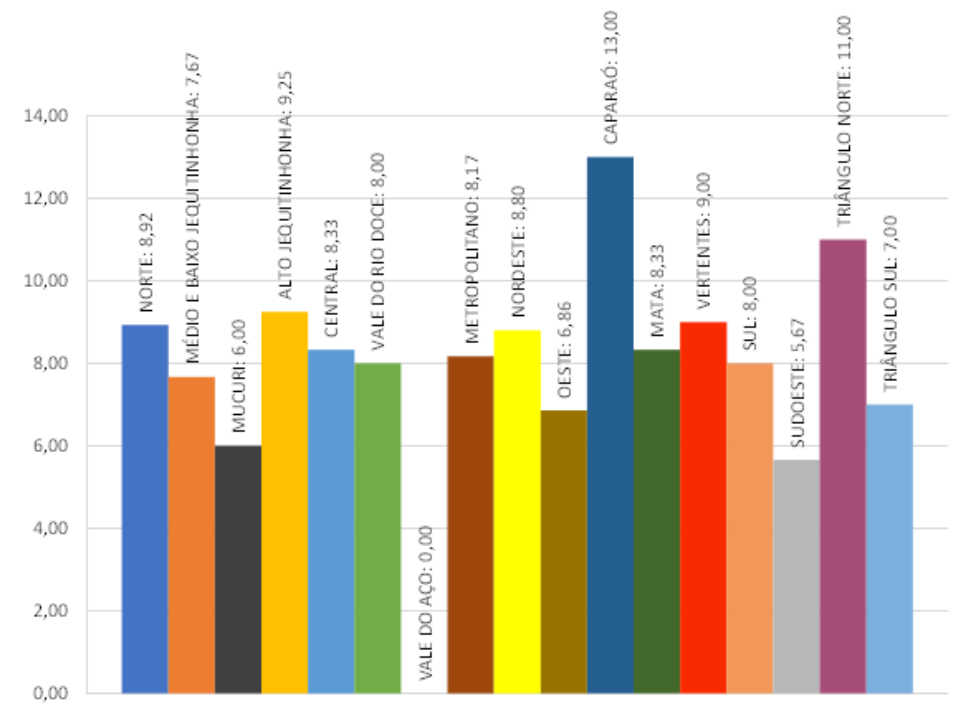

Fonte: IMRS, 2018. 
Como pode ser visto no Gráfico 2, nesse âmbito há maior proximidade dos valores apresentados, variando de 5,67 escolas (território Sudoeste) a 13 escolas (território Caparaó). Outro ponto, é que o território das Vertentes, que apresenta maior número da população acima de 25 anos com ensino médio completo, não é o território que possui o maior acesso à escolaridade.

Apesar do investimento maior em determinadas regiões visto na análise de gráfico relacionada ao "Gasto per capita com atividades de educação", elas não estão presentes com o maior percentual total de escolas que oferecem o ensino médio regular.

O território Caparaó sobressaiu apenas nesse gráfico, analisando outros dados da pesquisa, esse território possui maior população e é adjacente à Região Metropolitana, e a cada ano vem crescendo em matrículas no ensino médio (IBGE, 2012). O território Triângulo do Norte, por sua vez, se encontra entre os principais Territórios com IDHM de 0,729 (PNUD; IPEA; FJP, 2013). Esse território se destaca pelas suas atividades como a pecuária e artesanato em barro, e é uma região que tem seu PIB elevado (MINAS GERAIS, 2015). Terceiro território mais relevante, no tocante à atividade econômica do estado, o Triângulo Norte foi responsável pela geração de $9 \%$ do PIB mineiro em 2012, conforme o IBGE (2012). Na região, existem seus Distritos Industriais: Araguari, Ituiutaba, Patrocínio, Santa Vitória, Tupaciguara e Uberlândia, os quais contribuem para o crescimento da economia local.

Além de questões políticas, as propostas do governo para o ensino médio vivenciam também dificuldades para emplacar por causa de seu custo. Esse custo é difícil de ser absorvido pelos municípios, podendo ser uma possível razão pela variância apresentada pelos territórios no Gráfico 2. Como afirmam Boullosa e Schommer (2008), os fins sociais e os meios para conquistá-los não podem deixar de considerar diferentes indivíduos e suas necessidades em relações dialógicas.

O Gráfico 3 mostra a variável Gestão. Essa variável apresenta a gestão per capita por atividade de educação. O objetivo dessa variável é demonstrar o quanto os territórios estão investindo, por indivíduo, na educação. $\mathrm{O}$ aumento em gasto em educação está vinculado à melhoria na cobertura educacional. 


\section{Gráfico 3 - Gasto per capita com atividades de educação}

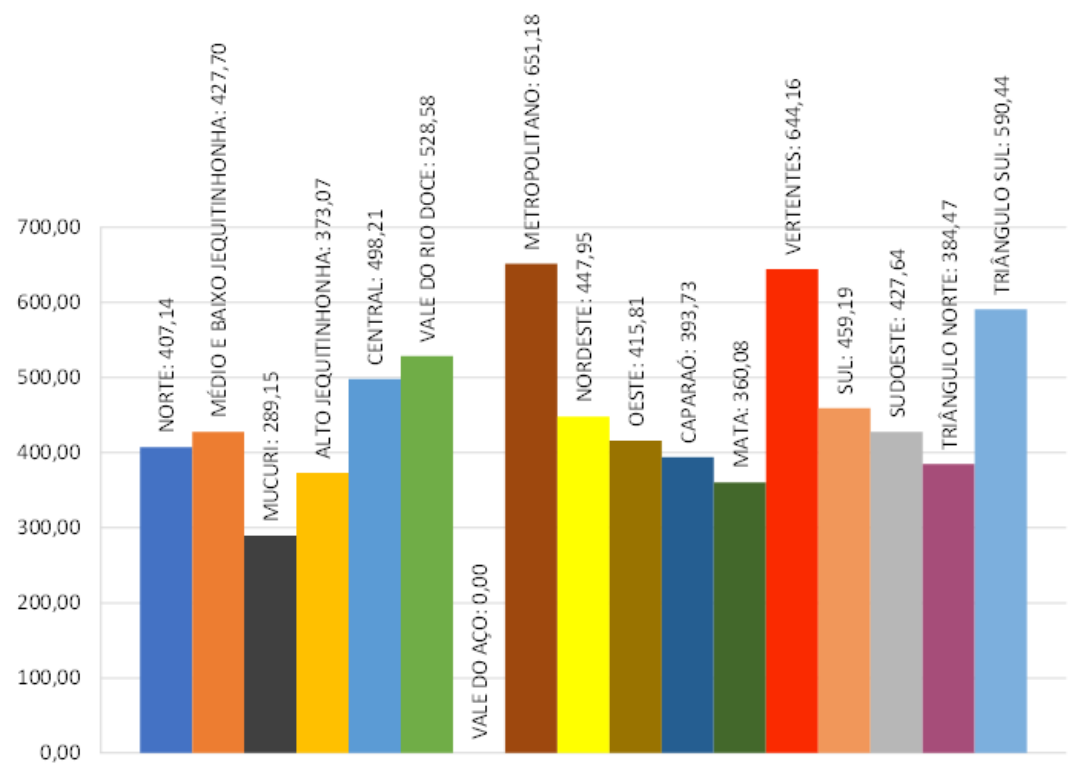

Fonte: IMRS, 2018.

No Gráfico 3, o território Metropolitano sobressaiu com R\$ 651,18, valor gasto per capita com atividades de educação. Na sequência, está o território das Vertentes e o Triângulo Sul. Apesar da alternância de posição, esse resultado corrobora com os dados apresentados para o maior percentual da população com 25 anos ou mais com Ensino Médio completo.

O território do Mucuri aparece com o menor gasto per capita com atividades de educação. Esse resultado demonstra a importância em identificar a região que possui ou não condições socioeconômicas para receber o ensino superior a distância e, ao mesmo tempo, trazer melhorias para a região.

O próximo construto a ser avaliado é Renda e Emprego. Iniciou-se pela variável Renda das Famílias. O Gráfico 4, mostra os dados dessa variável que apresenta a renda per capita das famílias nos Territórios. O objetivo dessa variável é demonstrar o quanto cada família possui de renda e por indivíduo. 


\section{Gráfico 4 - Renda per capita}

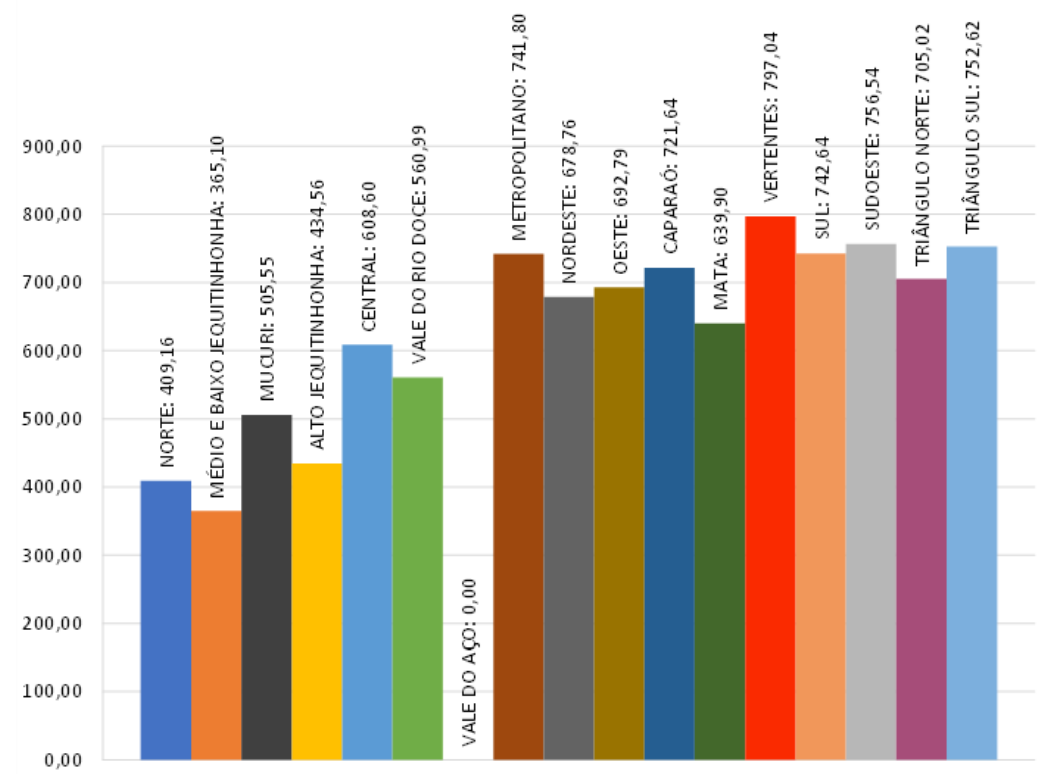

Fonte: IMRS, 2018.

No Gráfico 4 nota-se que o território com menor renda per capita é o Médio e Baixo Jequitinhonha, seguidos pelos territórios Norte e Alto Jequitinhonha. A partir do território Metropolitano até Triângulo do Sul os valores estão próximos de $\mathrm{R} \$ 700,00$ a $\mathrm{R} \$ 800,00$ assim, os dez últimos territórios dentro da análise gráfica têm o desenvolvimento e o crescimento econômico maiores. São destaques aqui o Território das Vertentes, Sudoeste e Metropolitano.

Deve-se pensar na análise em uma abordagem alternativa para a adversidade de desigualdade regional que se norteia na tese de que há relação com a concentração de indivíduos de baixa escolaridade e baixo capital, o que fazem com que suas rendas sejam menores. Assim sendo, a diminuição da desigualdade se confunde com luta contra a pobreza, que, precisa de uma política de educação e qualificação de profissionais (SALVATO, 2009).

Minas Gerais é o segundo estado brasileiro em número de habitantes e o quarto com a maior área territorial do país (IBGE, 2012). Ao analisar o Rendimento médio dos ocupados acima de 18 anos (Gráfico 5), nota-se que há uma oscilação considerável nesse item entre os territórios. O rendimento médio dos territórios está enquadrado entre $\mathrm{R} \$ 600,00$ até $\mathrm{R} \$ 1.300,00$. 
Os territórios das Vertentes e Triângulo Sul possuem quase o dobro do rendimento médio do território Médio e Baixo Jequitinhonha e do território Norte. Dos dezesseis territórios, dez possuem um rendimento médio maior que o salário mínimo atual $(\mathrm{R} \$ 998,00)$. Os demais territórios apresentaram um rendimento menor que o salário mínimo definido para o ano de 2019 (R\$ 998,00).

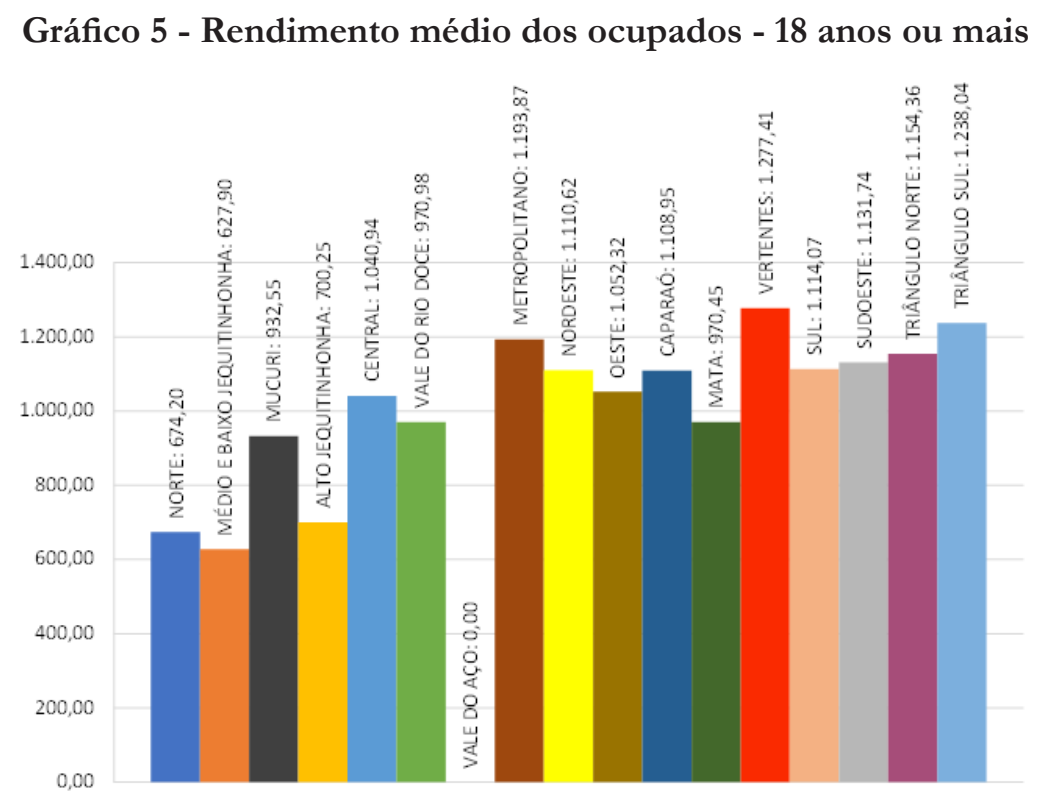

Fonte: IMRS, 2018.

Ao analisar a variável Gasto per capita total (Gráfico 6) busca-se demonstrar o gasto municipal total per capita para a geração de renda. Percebese que os territórios das Vertentes, Metropolitano e Triângulo Sul possuem os maiores investimentos per capita por parte dos municípios. Observa-se também, que o Médio e Baixo Jequitinhonha, Alto Jequitinhonha e Mucuri são os territórios com menor gasto per capita total. 


\section{Gráfico 6 - Gasto per capita total}

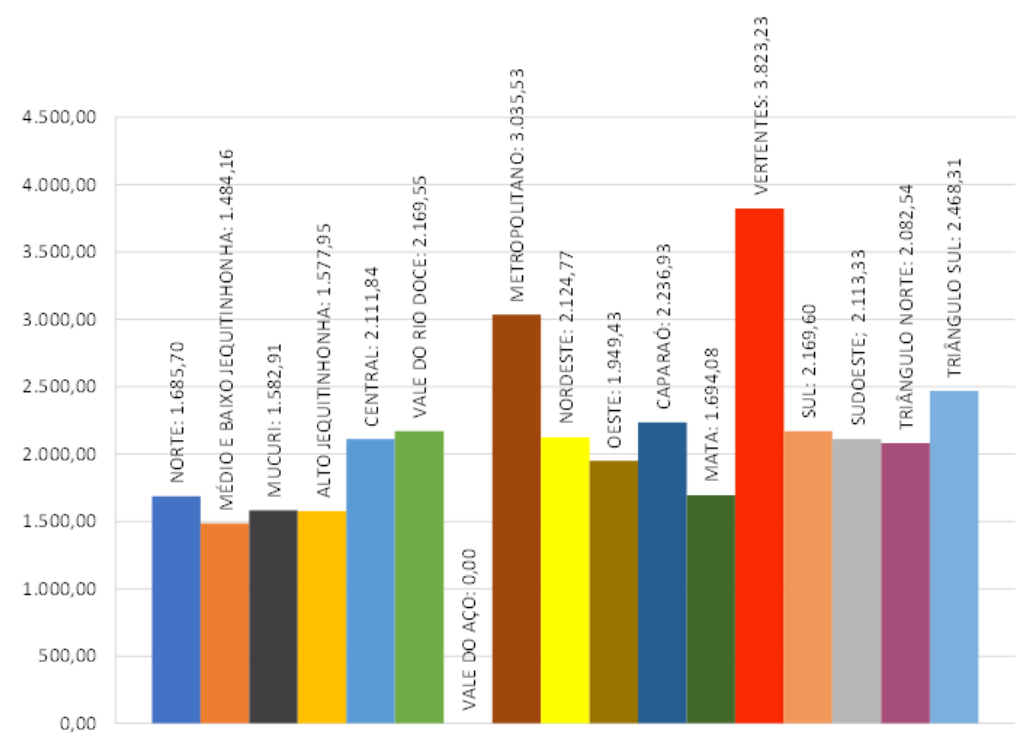

Fonte: IMRS, 2018.

Esse resultado demonstra a importância em identificar a região que possui ou não condições socioeconômicas para receber o ensino superior a distância e, ao mesmo tempo, trazer melhorias para o desenvolvimento local. Como afirma Souza (2015), a sociedade brasileira apresenta um cenário heterogêneo de desenvolvimento e desigualdades.

É certo que a dimensão do desenvolvimento local transcende a mensuração de variáveis econômicas ao levar em conta as potencialidades, aspectos culturais, sociais, naturais (TENÓRIO, 2010), por isso o estudo considera, dentre os dados disponíveis, questões de inserção dos indivíduos a partir da $\mathrm{EaD}$, de forma a integrar, ampliar o acesso e criar ações para transformação local (FISCHER et al, 2006), de forma a conquistar resultados mais estruturais. 


\section{CONCLUSÃO}

Esse estudo propõe uma análise dos fatores relevantes para as condições favoráveis para a expansão da educação superior à distância e que possuem como base as ordens econômica e social dos municípios mineiros que possuem de 30 mil a 100 mil habitantes. A definição dos indicadores adotada pelo estudo oferece aderência a fatores que possam vir a intervir em melhores condições para a expansão da educação mineira.

Situação recorrente em outros estados brasileiros, a desigualdade é revelada ao se analisar os gráficos e construtos do estudo. Os territórios mais próximos da Região Nordeste do Brasil se encontram em situação de maior vulnerabilidade, enquanto os territórios mais ao Sul, e também o Triângulo Mineiro, apresentam resultados mais altos em investimentos em educação, principalmente por estarem mais próximos à capital e por terem proximidade com territórios valorizados em termos econômicos como São Paulo e Rio de Janeiro.

Portanto, para que a intervenção se efetive, outras análises que somem dados integrando ao IDHM de cada um desses 85 municípios componentes destes Territórios fazem-se necessárias. Como apontam Souza (2015), Martins, Vaz e Caldas (2010) e Cançado (2013), no cenário heterogêneo de desenvolvimento e desigualdades da sociedade brasileira, as soluções perpassam muito além das questões meramente econômicas. As intervenções propostas poderão proporcionar aos municípios selecionados trocas de experiências acadêmicas, pesquisas, capacitações e fatores que implicam a promoção de uma educação de qualidade, diminuição da desigualdade e erradicação da pobreza, ampliando o desenvolvimento social.

Os municípios que compõem o território das Vertentes e o Metropolitano foram os que apresentaram condições socioeconômicas favoráveis para a expansão da educação superior a distância. Isso porque esses territórios apresentaram melhores índices de educação e renda. No que tange à educação, esses territórios apresentaram maior percentual da população com ensino médio completo, além de manifestarem maiores gastos per capita com atividades de educação. Já em relação à renda, os municípios desses territórios também apresentaram maior renda per capita. Logo, entende-se que é possível visualizar estudantes da modalidade EaD nos territórios mencionados, visto que os estudos corroboram com Pereira (2003) e Aretio (2002) que orientam essa modalidade para adultos com características heterogêneas na idade e nas competências, localizados em diferentes cidades, e que trabalham, sendo o estudo atividade secundária. 
Entretanto, há territórios como Caparaó, Sul e Mata que, mesmo não se destacando nas condições econômicas, possuem um percentual mediano da população com ensino médio completo. Logo, nesses territórios o ensino a distância pode proporcionar possibilidade de melhoria na renda. Os territórios Triângulo Sul, Triângulo Norte e Caparaó, apresentaram renda mediana, contudo, possuem um percentual abaixo dos territórios citados, da população com ensino médio completo. Os territórios com maior fragilidade socioeconômica (Médio, Baixo e Alto Jequitinhonha, Mucuri, Norte) possuem baixa perspectiva para a implantação da educação a distância.

Esse estudo aponta para novas pesquisas, sobretudo a partir do mapeamento sobre os territórios mineiros em todas as faixas de população, de forma a oferecer dados para o desenvolvimento educacional em nível superior. Outros estudos também poderão equacionar dados de infraestrutura tecnológica, bem como das próprias cidades, para fornecer condições de implantação e acesso a uma educação superior de qualidade, visando à formação cidadã e emancipadora.

\section{REFERÊNCIAS}

ANDRADE, Cibele Yahn de; DACHS, J. Norberto W. Acesso à educação por faixas etárias segundo renda e raça/cor. Cadernos de Pesquisa, São Paulo, v. 37, n. 131, p. 399-422, maio/ago. 2007.

ARAUJO, Victor; FLORES, Paulo. Redistribuição de renda, pobreza e desigualdade territorial no Brasil. Rev. Sociologia Política. Curitiba, v. 25, n. 63, p. 159-182, Set. 2017.

ARETIO, García Lorenzo. La educación a distancia: de la teoría a la práctica. Barcelona: Ariel, 2002.

BOULLOSA, R. F.; SCHOMMER, P. Limites da Natureza da Inovação ou Qual o futuro da Gestão Social? In: XXXII EnANPAD, Rio de Janeiro. Anais do XXXII Enanpad, 2008. v. 1.

CANÇADO, Airton Cardoso. Gestão Social: epistemologia de um paradigma / Airton Cardoso Cançado, José Roberto Pereira, Fernando Guilherme Tenório, 1. Ed. - Curitíba, PR CRV, 2013.

DEMO, Pedro. Educar pela pesquisa. 9. ed. rev. Campinas, SP: Autores Associados, 2011. 148 p. (Coleção Educação Contemporânea). 
FAHEL, Murilo; TELES, Leticia Ribeiro. Medindo a pobreza multidimensional do estado de Minas Gerais, Brasil: olhando para além da renda. Rev. Adm. Pública, Rio de Janeiro, v. 52, n. 3, p. 386-416, jun. 2018.

FAVARO, Neide de Almeida Lança Galvão; TUMOLO, Paulo Sergio. A relação entre educação e desenvolvimento econômico no capitalismo: elementos para um debate. Educação e Sociedade. Campinas, v. 37, n. 135, p. 557-571, Jun. 2016.

FISCHER, MELO, CARVALHO, JESUS, ANDRADE e WAIANDT. Perfis Visíveis na Gestão Social do Desenvolvimento. RAP. Rio de Janeiro. n. 40, v. 5, p.789-808, Set-Out. 2006.

FUNDAÇÃO JOÃO PINHEIRO (FJP). Centro de Estatística e Informações (CEI). Belo Horizonte: Fundação João Pinheiro, 2018. Disponível em: < http:/ / www.fjp.mg.gov.br. Acessos em 08 ago. 2018 e 04 out. 2018.

INSTITUTO BRASILEIRO DE GEOGRAFIA E ESTATÍSTICA (IBGE). Censo Brasileiro de 2010. Rio de Janeiro: IBGE, 2010.

Perfil dos Municípios Brasileiros. 2012. Disponível em: https://ww2. ibge.gov.br/home/estatistica/economia/perfilmunic/2012/. Acesso em $12 \mathrm{dez}$ 2018.

JUNQUEIRA, Luciano Antônio Prates; Gonçalves-Dias, Sylmara L. F., WANDERLEY, Mariangela Belfiore, MENDONÇA, Patrícia. Gestão social: mobilizações e conexões. Coleção Enapegs, vol. VI. São Paulo: LCTE Editora, 2012.

KAKWANI, N. \& SON, H. Poverty Equivalent Growth Rate. Review of Income and Wealth, 54(4), p. 643-655, 2008.

LEVY, A. \& CHOWDHURY, K.. A Geographical Decomposition of Intercountry Income Inequality. Comparative Economic Studies, 37(4), pp.1-17, 1995.

MARTINS, Rafael D’Almeida; VAZ, José Carlos; CALDAS, Eduardo de Lima. A gestão do desenvolvimento local no Brasil: (des)articulação de atores, instrumentos e território. Rev. Adm. Pública, Rio de Janeiro, v. 44, n. 3, p. 559590, Jun. 2010. 
MESQUITA, A.; SILVA, C.; SILVA, E.; OLIVEIRA, R. Assistência Social. In A.A. Valadares et al. eds. Boletim Políticas Sociais: Acompanhamento e Análise. V.23. Brasília: Instituto de Pesquisa Econômica Aplicada, 2015.

MINAS GERAIS. Fóruns Regionais. 2015. Disponível em: < http://www. forunsregionais.mg.gov.br/>. Acesso em: 04 out. 2018.

MOORE, M. G., KEARSLEY, G. Distance education: a systems view. California, USA: Wadsworth Publishing, 1996.

MOURA, Cleyton Domingues de. Subcidadania, desigualdade e desenvolvimento social no Brasil do século XXI. Revista Planejamento e Políticas Públicas. n. 34 | jan./jun. 2010, p. 67-86.

PEREIRA, Fernanda Cristina Barbosa. Determinantes da evasão de alunos e os custos ocultos para as instituições de ensino superior: uma aplicação na Universidade do Extremo Sul do Oeste. 2003. 172 f. Tese (Doutorado em Engenharia de Produção) - Programa de Pós-Graduação em Engenharia de Produção, Universidade Federal de Santa Catarina, Florianópolis, 2003.

PNUD - Programa das Nações Unidas para o Desenvolvimento; IPEA Instituto de Pesquisa Econômica Aplicada; FJP - Fundação João Pinheiro. O Índice de Desenvolvimento Humano Municipal Brasileiro. 2013. Disponível em: http://www.atlasbrasil.org.br/2013/pt/o_atlas/o_atlas_/. Acesso em $12 \mathrm{dez}$ 2018.

PRZEYBILOVICZ, Erico; CUNHA, Maria Alexandra; MEIRELLES, Fernando de Souza. O uso da tecnologia da informação e comunicação para caracterizar os municípios: quem são e o que precisam para desenvolver ações de governo eletrônico e smart city. Rev. Adm. Pública, Rio de Janeiro, v. 52, n. 4, p. 630-649, ago. 2018.

SACHS, Ignacy. De volta à mão invisível: os desafios da Segunda Cúpula da Terra no Rio de Janeiro. Estudos Avançados, v. 26, n. 74, p. 7-19, 2012.

SALVATO, M. A. Crescimento pró-pobre no Brasil: Uma avaliação empírica da década de 1990. Ensaios sobre pobreza, EP21, UFC, 2009. 
SANTOS, B. de S.; RODRÍGUEZ-GARAVITO, C. A. Introduction: expanding the economic canon and searching for alternatives to neoliberal globalization. In: SANTOS, B. de S. (Org.). Another production is possible. Beyond the capitalist canon. London: Verso, 2006. Disponível em: http://www. boaventuradesousasantos.pt/pages/ pt/livros/another-production-is-possiblebeyond-the-capitalist-canon.php

SILVA, M. O. S. Pobreza, desigualdade e políticas públicas: caracterizando e problematizando a realidade brasileira. Rev. Katál. Florianópolis, v. 13, n. 2, p.155-163, jul./dez. 2010.

SOUZA, Jessé (2009). A Ralé Brasileira: Quem É e Como Vive, Belo Horizonte: UFMG.

SOUZA, J. A tolice da inteligência brasileira: ou como o país se deixa manipular pela elite. São Paulo: LeYa, 2015.

SOUZA, Jessé. Em defesa da sociologia: o economicismo e a invisibilidade das classes sociais. Revista Brasileira de Sociologia. Vol. 1. N. 1. Jan-Jul., 2013.

TENÓRIO, F. G. Gestão Social: uma réplica. In RIGO, A. S.; SILVA JÚNIOR, J. T.; SCHOMMER, P. C.; CANÇADO, A. C. Gestão Social e Políticas Públicas de Desenvolvimento: Ações, Articulações e Agenda. Recife: UNIVASF, 2010.

TOLENTINO, R.S.S. et al. Avaliação na Qualidade da Educação a Distância sob a Perspectiva do aluno: proposição e teste de um modelo usando equações estruturais. Rege, São Paulo, v. 20, n. 3, p. 347-366, jul 2013.

VIEIRA, C.M.S.; ABREU, R.M.A. Educação a Distância: uma reflexão sobre a relação professor-tutor e estudante no processo de ensino e aprendizagem. Revista Intersaberes, v. 11, n. 23, p. 284-303, maio 2016. 


\section{Roberta de Cássia Macedo}

Doutora em Marketing, Estratégia e Operações (CEPEAD/FACE/UFMG) com ênfase em Gestão de Operações e Logística. Professora substituta na FACE/UFMG da área de Operações (Administração de Produção e Sistemas de Informação). Professora universitária nas disciplinas de operações/logística em instituições particulares desde 2006, sendo integrante do corpo docente da UNA desde 2012 ao corpo docente da Faculdade UNA de Contagem desde 2016. E-mail: roberta.c.macedo@gmail.com

\section{Daniela Viegas da Costa Nascimento}

Doutora em Administração pela PUC Minas. Professora e pesquisadora das áreas de gestão e de comunicação/marketing da graduação e pós-graduação do Centro Universitário UNA e da Faculdade UNA de Contagem. Membro do grupo de pesquisa: Núcleo de Pesquisas em Ética e Gestão Social (NUPEGS) do PPGA da PUC Minas. E-mail: dvcnascimento@gmail.com

\section{lara Vaz Vieira De Sousa}

Graduanda em Arquitetura e Urbanismo pelo Centro Universitário UNA. E-mail: iaravaziara@gmail.com 